http://jmscr.igmpublication.org/home/ ISSN (e)-2347-176x ISSN (p) 2455-0450

crossref DOI: https://dx.doi.org/10.18535/jmscr/v9i2.04

Journal Of Medical Science And Clinical Research

\title{
Evaluation of treatment of fractured Neck Femur with Fibular Grafting and Cancellous Hip Screw
}

\author{
Author \\ Dr Dilip Gupta (MS Ortho) ${ }^{1}$, Dr Narendra Kumar Chaudhary (MS Ortho) ${ }^{2}$ \\ Dr Rahmat Ali (Ms (Ortho), MCh (Ortho) ) 3* $^{*}$ \\ ${ }^{1}$ Sr.Consultant (Ortho), District Hospital, Basti, UP
}

${ }^{2}$ Assistant Prof. (Ortho Department), Maharishi Vashishtha Autonomous State Medical College, Basti, UP.

${ }^{3}$ Professor and H.O.D (Ortho Department), Maharishi Vashishtha Autonomous State Medical College, Basti, UP, India

*Corresponding Arthur

Dr Rahmat Ali (Ms (Ortho), MCh (Ortho) )

Professor and H.O.D (Ortho Department), Maharishi Vashishtha Autonomous State Medical College, Basti, UP, India

\begin{abstract}
"We come into the world under the brim of the pelvis and go out through the neck of the femur"William Felding (1964). This phrase speaks volumes regarding the bleak outlook and grave prognosis of fractures of the femoral neck till the early years of the twentieth century it was in a nutshell "the death blow to an old individual" It was little wonder, therefore, that the Smith Petersen nail was received sixtyfive years ago as the panacea for femoral neck fractures as a welcome departure from Whitman's closed method of treatment. The treatment of these fractures is so fraught with failures that it has been have labelled as the unsolved fracture. The complex biomechanics acting at the upper end of the femur, the enrolling of synovium into the fracture site, synovial fluid washing away of the fracture haematoma and scanty blood supply to the femoral head all contribute to the high failure rates and unpredictable results. The rationale of treatment of closed fracture neck femur with fibular graft is based upon -: Decompression of the femoral head, interrupting the cycle of ischemia and interosseous hypertension, Removal of necrotic bone, grafting of the defect with fresh cortico-cancellous bone, Placement of a viable cortical bones strut to support the subchondral surface to prevent collapse and enhance the revascularization process by providing a source of mesenchymal stem cells.
\end{abstract}

Keywords- $A b d, A d d, A V N, A P, C O R R, F W B$, inf, JBJS, NWB, PWB, SLR, Tend.

\section{Introduction-}

Fracture of the femoral neck continue to be a difficult problem Sir Astley Cooper (1824) has stated in his treatise on fractures "In all the examinations which I have made of fractures of the cervix femoris entirely within the capsular ligament, I have never met on in which a bony union had taken place or which did not admit of motion of one bone upon the other" However Robert Smith (1854) wrote that Osseous Union in intracapsular fracture is most likely to occur when the fractures is impacted. This observation 
was made long before Roentgenograms were invented. Whitman (1902) in the early years of the 20th century suggested that if the fragments were brought into same plane by traction of limb. In ward rotation and full abduction, tension in the capsule would adjust them and end to end apposition would result. This method was known as "abduction treatment" and was modified by Leadbetter (1932). The turning point in surgical management of fracture neck femur came with Smith Petersen's (1931) nailing procedure by using a triflanged nail and nailing its surgical approach by using anatomical places. The triflanged nail without a side plate however, does not stop the distal fragment from rotation nor does it prevent the head from drifting into varus position.Austin Moore (1934) inserted four pins in cross fashion to stop rotation: To prevent their penetration through the head, their outer portions were threaded to receive four bevelled nuts. He later recommended that the pins be placed as parallel as possible to allow some backward impaction of the head into the neck.

Thornton (1937) improved internal fixation by adding a side plate to the Smith Petersen nail. This was later strengthened by Me Laughlin (1947) this two-piece unit was joined by a variety of bolts and washers Its main disadvantage was its weakness at the nail plate junction. Asnis (1980) developed a guided screw system with two goals 1) to build a screw specifically designed to improve fixation in the multiple pin treatment of intracapsular fractures 2) to provide a system that accurately places multiple parallel guide pins over which cannulated compression screws can be placed.

\section{Material and Methods}

36 patients attending the outpatient Department of Orthopaedics in District Hospital, Basti. Form this study between Dec 2019 to Dec 2020 and a retrospective analysis of previous cases of fracture neck femur treated by fibular grafting and cancellous hip screws A detailed evaluation of the patient was carried out on admission paying special attention to any associated injuries and medical illness. If the condition of the patient required pre-operative build-up the fractured limb was immobilised by upper tibial pin traction (or above knee skin traction). Routine blood and urine examinations were carried out and any associated medical condition was adequately dealt with the patient was then subjected to pre-anaesthetic check-up and posted for surgery as early as possible.

\section{Pre-operative evaluation of Patient}

General History, General examination, Systemic examination, Local examination, Lab investigation and Radiological examination To Asses:- Radiological signs of union \& Radiological signs of AVN of femoral head.

\section{Instruments used for operation}

Cannulated cancellous screw of various sizes, Drill Bit, Guide Wire, Measuring device, Tap, Trochanteric Reamer, Oscillating Saw, Drill Machine, Hexagonal Screw Driver, Osteotomes, Hammer, other General Instruments.

\section{Pre-Operative Preparation}

Thorough cleaning of the operative sites that is the involved hip and the donor site of the fibula was carried out the evening prior to the day of surgery. The parts were then painted with Betadine lotion and kept in sterile dressing. The radiographs of the pelvis with both hips, anterior posterior view and the lateral view of the involved hip were taken preferably just prior to the surgery.

\section{Methods}

\section{Surgical Procedure}

Under proper aseptic precaution and adequate anaesthesia closed reduction of fracture neck femur by either the Whitmann's lead batter or Flynn method was performed Check AP and lateral radiograph were taken with a C-Arm fluoroscopic unit. One team of surgeons exposed the proximal femur through a curved antero-lateral incision splitting the interval between the tensor 
fascia Lata and the gluteus Medius the origin of the vastus lateralis is reflected to expose the lateral femur and approximately $5 \mathrm{cms}$ of the vastus lateralis is reflected from the linea aspera. After identifying the base of the greater trochanter a3 $\mathrm{mm}$. guide pin is inserted approximately $2 \mathrm{cms}$ distal to the vastus ridge and under fluoroscopic guidance is directed into the centre of femoral neck Care is taken to ensure that there is enough space between the guide pin and cortex of the neck to allow a reamer of adequate diameter to pass Cannulated reamers are progressively passed over the guide pin starting with a $10 \mathrm{~mm}$ reamer. Healthy bone from the trochanter and neck is saved for grafting Cancellous bone graft is placed into the cavity with the use of a custom- made impaction device. Then tapping is done with cannulated tap. The appropriate length of screw is then inserted with the help of cannulated screw driver.

\section{Fibular Harvest}

The donor site for fibula is preferably chosen on the contra lateral leg because of ease of operation by two separate teams Standard Henry's posterolateral approach for the fibular shaft was utilized toexpose fibula. The desired length of fibula from the mid shaft was taken out (depending on the length of guide wire inside the proximal femur) by ostectomising it with osteotome or with Gigli's saw after making drill holes through it at desired ends. One end of graft was bevelled for ease of insertion into the head and neck of femur. The graft was used immediately after removal without any preservation.

\section{Placement of the fibular graft}

Fibular is inserted with the broadest surface in the AP plane and gentle impaction. Prior to impaction, a final cancellous plug is placed in the distal aspect of the tunnel Final position of the graft is confirmed and the fluoroscope unit is removed, The wound is closed in layers over a negative suction drain.

\section{Follow-up}

On first follow-up at four weeks, the wounds were inspected for any evidence of infection, the thigh, leg and foot were inspected for swelling and tenderness and AP and lateral radiographs of the operated hip were taken If the condition of the patient permitted the patient was advised to perform active non weight bearing exercises of the hip and knee in the bed. After the first year, the patient was called for follow-ups at six monthly intervals with the instruction to report immediately in the case of any pain in the hip region.

\section{Results}

Forty-two cases of intra capsular fracture neck fout in patients both (prospectively and retrospectively) were taken up for the study between Dec 2019 to Dec 2020 at the Department of Orthopaedics. District Hospital, Basti in all prospective cases (21 cases) Fibular grafting with cannulated cancellous hip screws fixation was done. Six of the cases were lost to follow-ups and therefore have been excluded from the evaluation of results. The retrospective analysis (12 cases) included cases of femoral neck fracture treated earlier by cannulated cancellous hip screws (2 parallel screws). During the observation of group, I in 12 patients $(66.64 \%)$ union was achieved within a short period of 3-6 months. In three patients, the fracture united by six to nine and in a single case delayed union occurred at 9 months. In two patients, unfortunately the fracture did not unite. While during the observation of Group II only in patients $(38,89 \%)$ union was achieved within a short period of 3-6 months. In five patients the fracture united by six to nine and in two cases delayed union occurred at 9 months. Non-union, avascular necrosis, joint stiffness and shortening were the main complications encountered in one case the fracture was fixed in Coxa valga and lengthening ensued while in two cases there was coxa vara and shortening in six cases. In the final tally satisfactory results were obtained in 13 cases of group I and 9 cases of 
group II. In 2 cases of group I, the fracture united in malposition with appreciable restriction of joint motion or early avascular necrosis resulted in pain on exertion.

\section{Discussion}

Intracapsular fracture neck femur was described as the unsolved fracture" by Dickson (1953) while Barnes (1964) had remarked that many surgeons regarded it as the unsolvable fracture" Till date, this fracture has remained the unquenched thirst for Orthopaedic surgeons the world over. Through the ages various enchanting modes of treatment of these fractures have evolved, none of which are fool proof the concept of treatment has undergone a sea change from dogmatic conservatism at the turn of the century to an absolute faith in internal fixation today. The concept of inlay grafting of cortical bone providing stability with osteosynthesis, in the inherently weak bone of the femoral neck appears to be a logical mode of treatment. This study was an attempt to evaluate the efficacy of fibular inlay grafts, with supplementary fixation, in the treatment of intracapsular fracture neck femur in the relatively younger age group. The mean age of the patients in this series was 2833 years which was less compared to that of western studies.. Early onset of osteoporosis in Indian patients ruled out the feasibility of osteosynthetic surgery above 60 years of age. In the present study, males tar outnumbered females while sustaining intracapsular fracture neck femur. The females of post-menopausal age have relatively weaker osteoporotic bone and are therefore more liable to sustain hip fractures after trauma: In Indian circumstances, the society is still male dominated and males being more mobile. are more likely to sustain trauma Moreover, poverty and literacy, the banes of rural Indian society ensure that many female patients do not seek treatment at all Hence in Indian studies, the incidence of fracture is higher in males.

In almost all the cases partial weight bearing on crutches was advised at around six to eight weeks, provided the patient was able to initiate active SLR without pain. Full weight bearing was commenced only after radiological union. Two patients with advanced degree of avascular necrosis had persistent pain in the hip which forced them to walk with a stick. Two cases failed to unite at the time of final follow-ups and both had Pain which hindered their daily routine. However, it was noteworthy that the union between both the fibular grafts and the trochanteric site and between the single well positioned graft and the head and neck was very firm, which was confirmed on revision surgery. However attractive the procedure may appear; it is not without certain distinct disadvantages: 1) The procedure requires perfect technical skill and cohesive team work of surgeon and radiologist which is not available every time and everywhere. It will not be out of place to over emphasize the following absolute prerequisites for good results. a. Near Anatomical reduction.b. Exactly parallel guide wires. c. Trans fixation of the head with guide wires. d. Perfect lateral view radiograph. e. Proper length of fibular graft, f. Strict follow-up of the patients.

\section{Summary}

A study of the efficacy of fibular grafting procedures in 8 cases of intracapsular fracture neck femur was taken up in the Department of Orthopaedics, District Hospital, Basti from Dec 2019 to Dec 2020. Review of the available literature was done up to 2020. Intracapsular femoral neck fractures were found to be increasingly common in younger patients, the mean age being 28.33 years Males were the main sufferers. Garden's Grade III was the commonest type of fracture followed by Garden's Grade IV and Grade Il respectively. The earliest union was seen in six and half weeks and the mean union time was 3.24 months in our series 16 cases united while two cases went into non-union.

\section{Conclusion}

Fibular grafting with cannulated cancellous screw 
fixation gives excellent results in comparison to fixation only with cannulated cancellous hip screw. The osteoporotic bone of the fractured neck femur heals better in the homogenous medium provided by autogenous fibular grafts. (BONE IS HUNGRY FOR BONE).

\section{Reference}

1. Arnold. W.D., Lyden. J.P., Minkoff, L.: Treatment of intracapsular fracture of the femoral neck J.B.J.S. 56A, 254, 1974.

2. Ayer A.:Treatment of intracapsular fracture with new compassion device JBJS. 45B, 806. 1963.

3. Baksi D.P. Choudhary A.K., Chatterjee N.D.: Different osteotomies and internal fixation with muscle pedicle bone grafting in the treatment of ununited femoral neck fractures. IJO 55-60, 1992.

4. Baksi D.P.: Treatment of osteonecrosis of the femoral head by drilling and muscle pedicle bone grafting. J.B.J.S. Br. 73, 241245, 1991.

5. Boyd H.B. \& Salvatore J.E.: Acute fracture of the femoral neck. Internal fixation or prosthesis J.B.J.S., 46A, 1066, 1964.

6. Campbell W.C.: The autogenous bone graft JBJ.S. 21, 3 July 1939.

7. Carrel W.B.: Transplantation of fibula in the same leg. B.J.S,3, 627, 1938.

8. Chacha P.B, Ahmed M., Daruwala J.S.: Vascular graft of the ipsilateral fibula for non-union of tibia. J.B.J.S, 638, 246-253, 1981.

9. Charnley Sir John: The treatment of displaced fracture of neck of the femur by compression J.B.J.S. 39B, 1, 45, 1957.

10. Chung S. M.K.: The arterial supply of the developing proximal and of the human femur. J.B.J.S., 58A, 951, 1956.

11. Clark D.I., Crofts C.E. \& Saleh M.: Femoral neck fracture fixation J.B.J.S., 72B, 5, 1990.
12. Clarke 1.C. \& Amstutz H.C.: Human hip joint geometry and hemiarthroplastic selection in the hip in proceedings of the third scientific meeting of the hip society 1975 St. Luis: 63.

13. Cleveland M. \& Fielding J.W.: intracapsular fracture of the neck of the femur Vol. 12. Ann Arbor, J.W. Edwards, 1955.

14. Compere E.L. \& Lee J.: Restoration of physiological and anatomical function in ununited intracapsular fraction of the neck femur J.B.J.S., 22, 261-277, 1940.

15. Deyerle W.M.: Absolute fixation of fracture of the hip with contact compression. Anew fixation device. Clinical ortho. 13, 279, 1959.

16. Deyerle W.M.: Multiple pin peripheral fixation in fraction of neck of femurimmediate weight bearing. Clinical ortho. 39, 1965.

17. Dickson J.A.: Treatment of ununited fracture of neck of the femur by means of bone graft and Smith Petersen nail, S.CNA. 19. 1235, 1939.

18. Fairbank A.C. Bhatia D., Jinnah R.H., Hungerford D.S.: Long term results of core decompression for ischemic necrosis of the femoral head, J.B.J.S. Br. 77, 42-49, 1995.

19. Henderson M.S. \& Henderson E.D.: Bone grafts for ununited fractures of neck of the femur - a report of 90 cases J. Internal Coll Surge 9, 26-34, 1946.

20. Kane S.M., Ward W.A., Joedan L.C., Guilford W.B. \& Hanley E.N. Jr: Vascularized fibular grafting compared with core decompression in the treatment of femoral head osteonecrosis: Ortho 19, 869-872, 1996. 